\section{Study Pinpoints Sources of Polluting Vehicle Emissions}

\author{
Unburned lubricant produces $60 \%-90 \%$ of organic \\ carbon emissions.
}

While diesel fuel is often viewed as the most polluting of conventional petroleum-based fuels, emissions from gasoline engines can more significantly degrade air quality. Gasoline exhaust is at least as toxic on a per-unit-mass basis as diesel exhaust, and contributes up to 10 times more particulate matter (PM) to the emission inventory. Because emissions from both fuels can gravely impact health and the environment, researchers at the National Renewable Energy Laboratory (NREL) launched a study to understand how these pollutants relate to fuels, lubricants, and engine operating conditions.

NREL's Collaborative Lubricating Oil Study on Emissions (CLOSE) project tested a variety of vehicles over different drive cycles at moderate $\left(72^{\circ} \mathrm{F}\right)$ and cold $\left(20^{\circ} \mathrm{F}\right)$ temperatures. Testing included:

- "Normal" and high-emitting light-, medium-, and heavy-duty vehicles

- Gasoline, diesel, and compressed natural gas (CNG)-powered vehicles

- New and aged lubricants representative of those currently on the market

- Gasoline containing no ethanol, E10, Texas-mandated low-emission diesel fuel, biodiesel, and CNG

The study confirmed that normally functioning emission control systems for gasoline light-duty vehicles are very effective at controlling organic carbon (OC) emissions. Diesel vehicles without aftertreatment emission control systems exhibited OC emissions approximately one order of magnitude higher than gasoline vehicles. High-emitter gasoline vehicles produced OC emissions similar to diesel vehicles without exhaust aftertreatment emission control. Exhaust catalysts combusted or converted more than $75 \%$ of lubricating oil components in the exhaust gases.

Unburned crankcase lubricant made up 60\%-90\% of OC emissions. This OC represented $20 \%-50 \%$ of emitted PM in all but two of the vehicles.

Three-way catalysts proved effective at reducing most of the OC. With high PM emitters or vehicles with deteriorated aftertreatment, high-molecular-weight fuel components and unburned lubricant were emitted at higher rates than in vehicles in good repair, with functioning emissions systems.

Light-duty gasoline, medium-duty diesel, and heavy-duty natural gas vehicles produced more particles with fresh oil than with aged oil. The opposite trend was observed in lightand medium-duty high PM emitters. This effect was not readily apparent with heavy-duty diesel vehicles, perhaps because the lubricant represented a much smaller fraction of the total PM in those trucks.

Technical Contact: Wendy Clark, wendy.clark@nrel.gov

Reference: Carroll, J.N.; Khalek, I.A.; Smith, L.R.; Fujita, E.; Zielinska, B. (2011). Collaborative Lubricating Oil Study on Emissions: November 28, 2006-March 31, 2011. NREL Report No. SR-5400-52668. http://www.nrel.gov/docs/fy120sti/52668.pdf.

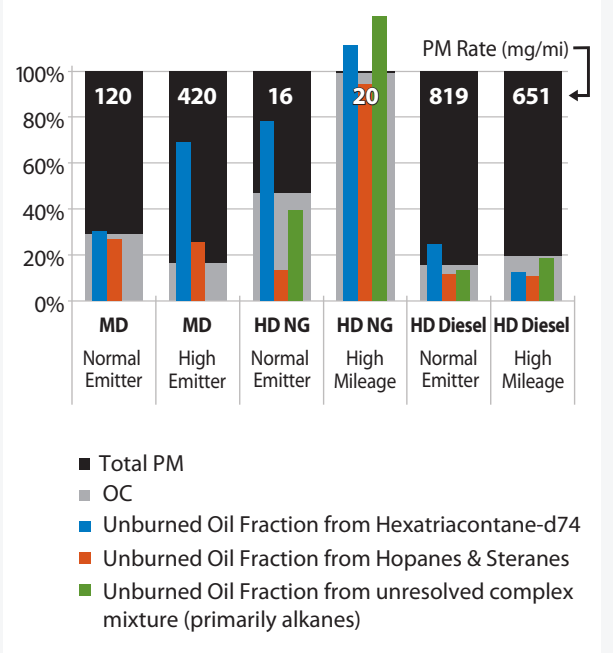

Average $O C$ and unburned oil as fractions of total PM.

\section{Key Research Results}

Achievement

The CLOSE study quantified the relative contributions of fuels and engine lubricating oil on PM and semi-volatile organic compound emissions from in-use motor vehicles powered with a range of petroleum-based fuels.

Key Result

While existing emission control systems are already quite effective in most light-duty vehicles, high-emitter gasoline vehicles can produce emissions comparable to diesel vehicles without exhaust aftertreatment control.

Potential Impact

These findings will help focus future research and development efforts on technology improvements that will deliver the greatest reduction in emissions.

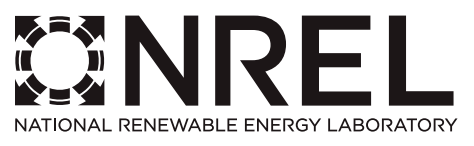

BNREL

15013 Denver West Parkway | Golden, CO 80401 | 303-275-3000 | www.nrel.gov
NREL is a national laboratory of the U.S. Department of Energy, Office of Energy Efficiency
and Renewable Energy, operated by the Alliance for Sustainable Energy, LLC. NREL/FS-5400-52010 • March 2012 